\title{
Catamenial Genital Herpes is prevented by transdermal estradiol treatment of severe Premenstrual Syndrome (PMS)
}

Peter Greenhouse FRCOG FFSRH peter.greenhouse@nhs.net

Weston Integrated Sexual Health Centre, Weston-super-Mare, UK

Transdermal estradiol is a first-line treatment for severe PMS',

and is effective against other catamenially-triggered problems such

as menstrual migraine. Many women with genital herpes get regular

premenstrual recurrences, which were known classically as "Herpes

menstrualis" or "Bouton de Règles" (Unna 1883): This has been prevented

by using aciclovir only in the luteal phase ${ }^{2}$ : Yet we could find nothing in the

English-language scientific literature on catamenial genital herpes (CGH).

AIM: We set out to test a simple biologically plausible principle that:

\begin{tabular}{|l}
\hline \hline $\begin{array}{l}\text { "If any physical or mental symptom has a precisely repeating cyclical timing, } \\
\text { then it must have a hormonal cause, so it could have a hormonal solution" }\end{array}$ \\
\hline \hline
\end{tabular}

We observed changes in genital herpes recurrence rates in perimenopausal women who stopped taking aciclovir and started transdermal estradiol treatment for severe premenstrual syndrome.

METHODS: Proof of concept study reviewing notes of 15 perimenopausal women median age 41 years (range 36-46) seen between 2005-17, each meeting the criteria for severe PMS. Each had experienced at least 4 consecutive monthly episodes of CGH (culture or PCR-proven HSV2) before starting luteal-phase aciclovir suppression, then all switched to transdermal 17beta estradiol gel (Sandrena ${ }^{\circledR}$ ) $0.5 \mathrm{mg}$ daily for 14 days luteally or every day continuously for those using Mirena ${ }^{\circledR}$ (LNG-IUS).

Subjects self-reported mood parameters and herpetic symptoms with a modified daily symptom chart over nine months follow-up during which no aciclovir was taken pre-emptively, but was available in case of episodic recurrence.

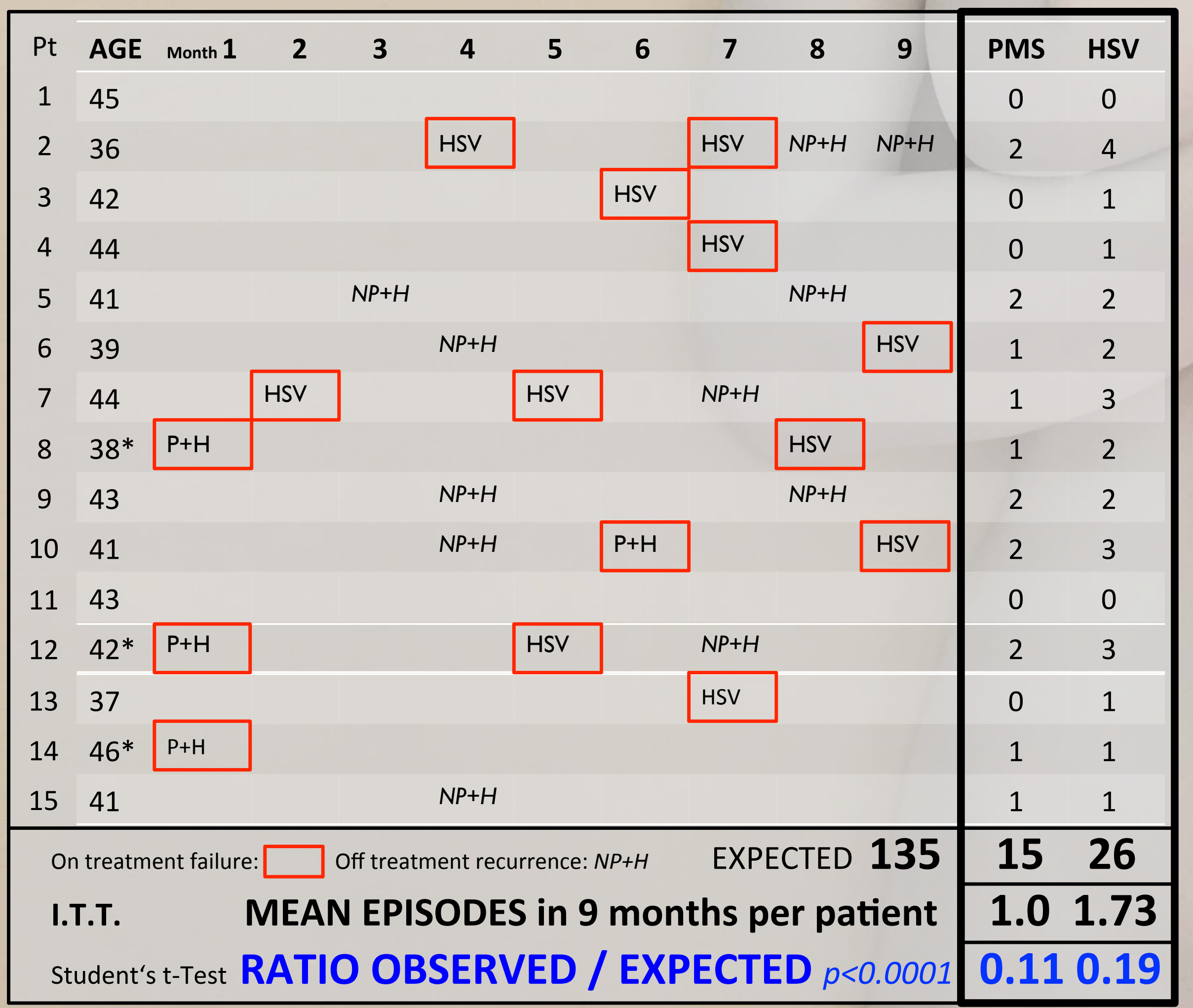

\section{CONCLUSIONS:}

Transdermal estradiol treatment is a novel and effective method of preventing premenstrually recurrent genital herpes.

It works by stabilising the hormonal milieu, suppressing cyclical reductions of ovarian estradiol which normally downregulate T-helper 1 cells in the luteal phase, causing catamenial immunosuppression, which is exacerbated in the perimenopause.

- Most women with severe perimenopausal PMS are seen by family doctors who prescribe ineffective SSRI drugs.

- Most women with catamenial herpes are seen in sexual health clinics and offered only suppressive or episodic aciclovir. This study proves the concept that both problems can be managed effectively by an integrated approach to women's health.

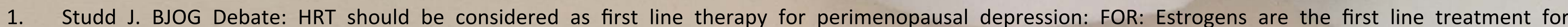
perimenopausal women. BJOG 2016: 123; 1011

2. Greenhouse P, Evans AE. Premenstrually-recurrent genital herpes in perimenopausal women: Prevention by luteal phase aciclovir. ISSTDR Amsterdam 2005

\section{ANALYSIS:} where estradiol treatment was omitted in error and both conditions recurred in each untreated cycle.

(NP+H on table)

\section{RESULTS: - see table}

All women experienced substantial or complete relief of PMS in all but four cycles when oestradiol treatment was correctly taken.

Three women* in whom mood the first month, responded successfully when the estradiol dose

Only 15 symptomatic herpes episodes occurred when estradiol treatment was correctly taken over 124 woman-months of observation. 